\title{
Quantitative evaluation of the immunodeficiency of a mouse strain by tumor engraftments
}

Wei Ye ${ }^{1,2+}$, Zhiwu Jiang ${ }^{1,2+}$, Guan-Xiong Li ${ }^{3}$, Yiren Xiao ${ }^{1,2}$, Simiao Lin ${ }^{1,2}$, Yunxin Lai ${ }^{1,2}$, Suna Wang ${ }^{1,2}$, Baiheng Li ${ }^{1,2}$, Bei Jia ${ }^{4}$, Yin Li $i^{5}$, Zhi-liang Huang ${ }^{6,7}$, Jin Li $i^{8}$, Fenglan Feng ${ }^{8}$, Shuhua Li ${ }^{9}$, Huihui Yao ${ }^{10}$, Zixia Liu ${ }^{11}$, Su Cao ${ }^{12}$,

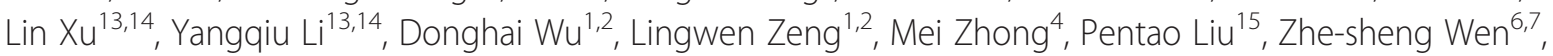
Bing $\mathrm{Xu}^{5}$, Yao Yao ${ }^{16}$, Duanqing Pei ${ }^{1,2,17^{*}}$ and Peng $\mathrm{Li}^{1,2,17^{*}}$

\begin{abstract}
Background: The mouse is an organism that is widely used as a mammalian model for studying human physiology or disease, and the development of immunodeficient mice has provided a valuable tool for basic and applied human disease research. Following the development of large-scale mouse knockout programs and genome-editing tools, it has become increasingly efficient to generate genetically modified mouse strains with immunodeficiency. However, due to the lack of a standardized system for evaluating the immuno-capacity that prevents tumor progression in mice, an objective choice of the appropriate immunodeficient mouse strains to be used for tumor engrafting experiments is difficult.
\end{abstract}

Methods: In this study, we developed a tumor engraftment index (TEI) to quantify the immunodeficiency response to hematologic malignant cells and solid tumor cells of six immunodeficient mouse strains and C57BL/6 wild-type mouse (WT).

Results: Mice with a more severely impaired immune system attained a higher TEl score. We then validated that the NOD-scid-IL2Rg-/- (NSI) mice, which had the highest TEI score, were more suitable for xenograft and allograft experiments using multiple functional assays.

Conclusions: The TEI score was effectively able to reflect the immunodeficiency of a mouse strain.

Keywords: Immunodeficiency, Tumor, Leukemia, Xenograft, Allograft

\section{Background}

Research on human diseases has relied on experiments using immunodeficient mouse models [1]. The derivations of nude and severe combined immunodeficiency (scid) mice, which are widely used for xenotransplantation, were milestones in the development of immunodeficient mice. However, although nude mice lacked $\mathrm{T}$ cells, they harbored B cells and natural killer (NK) cells and did not allow lasting human cell reconstitution [2]. The limitations that impeded human cell engraftment in scid and recombination-activating 2 deficient (Rag2-/-) mice included the remaining mouse $\mathrm{T}$ and $\mathrm{B}$ cells and

\footnotetext{
*Correspondence: pei_duanqing@gibh.ac.cn; li_peng@gibh.ac.cn

${ }^{\dagger}$ Equal contributors

'Key Laboratory of Regenerative Biology, South China Institute for Stem Cell Biology and Regenerative Medicine, Guangzhou Institutes of Biomedicine and Health, Chinese Academy of Sciences, Guangzhou 510530, China Full list of author information is available at the end of the article
}

high levels of host NK cells [3, 4]. The development of NOD.Cg-Prkdc scid (NOD-scid) mice with lower levels of NK cells and additional innate immune defects allowed higher levels of human cell engraftment, but the mice were still not ideal [5]. A major breakthrough in the generation of humanized mice was the development of immunodeficient IL2Rg-/- mice, such as the NOD/ ShiLtSz-scid/IL2R $\gamma^{\text {null }}$ (NSG) and NOD/ShiJic-scid/IL2R ${ }^{\text {null }}$ (NOG) strains. These mice withstood greatly increased engraftments of human tissues (hematopoietic stem cells (HSCs) and peripheral blood mononuclear cells (PBMCs)) than all previously developed immunodeficient humanized mouse models [6, 7]. Cancer cells and the host immune system constantly interact with one another in the tumor microenvironment $[8,9]$. Clinical data have demonstrated that immunodeficient individuals are susceptible to a dramatic increase in tumor incidence. For example, the 
occurrence of leukemia was higher in immunodeficient patients compared with the general population [10]. Consistently with immunodeficient patients, STAT-1-/and RAG-/- mice showed a significantly increased incidence of observable cancers compared with their nonimmunodeficient counterparts $[11,12]$. Thus, a greater severity of immune deficiency led to a greater degree of tumor growth in immunodeficient mice.

Following the development of large-scale mouse knockout programs [13] and genome-editing tools, such as zincfinger nuclease (ZFN) [14], transcription activator-like effector nuclease (TALEN) [15-17] and the type II clustered, regularly interspaced, short palindromic repeat (CRISPR)-associated (Cas) system [18-20], it has become increasingly efficient to generate genetically modified mouse strains that cannot easily be generated using traditional hybridization [21]. However, because no standardized system for evaluating immunodeficiency in mice currently exists, an objective comparison of the immunodeficiency of various immunodeficient mouse strains is difficult.

In this study, we developed a tumor engraftment index (TEI), using six representative immunodeficient mouse models, combining the hematopoietic and solid tumor model and the allograft and xenograft models, and created a statistical formula for a simple and accurate method to quantify the immunodeficiency of mouse strains. We showed that the NOD-scid-IL2Rg-/- (NSI) mice had the highest TEI scores in both the xenograft and allograft tests. Moreover, we validated the TEI scoring results using human-derived HSC, human bone marrow/liver/thymus (BLT), single primary B cell acute lymphoblastic leukemia (B-ALL) cell transplantation models, and primary tumors from lung cancer patients.

\section{Results}

\section{Assessing the ability to prevent the engraftment of hematological tumors}

Immunodeficiency is positively correlated with the capacity for tumor engraftment [22, 23]. We chose C57BL/6 wild-type (WT) and six well-characterized immunodeficient mouse strains, namely nude [2], scid [3], NOD-scid [5], B6.129S4-IL2Rg-/- (IL2Rg-/-) [24], Rag2-/- [4], and NOD-scid-IL2Rg-/- $[5,7]$ mice, to assess immunodeficiency. Because the NSG and NOG strains are not commercially available in China, we generated the NOD-scid-IL2Rg-/- (NSI) strain, which did not harbor $\mathrm{T}$, B, or NK cells, by TALEN-mediated gene targeting in the NOD background [25].

For an accurate quantification, we first evaluated the immunodeficiency of a mouse strain by measuring its ability to prevent hematologic tumor engraftment. We injected K562-GFP cells [26], a human chronic myeloid leukemia cell line with Philadelphia chromosome, which constitutively expressed green fluorescent protein (GFP) (Additional file 1: Figure S1) into the seven mouse strains without any preconditioning, and assessed the percentages of tumor cells in certain tissues of the recipients. Three groups of mice (five mice per group) were assayed with a high number $\left(1 \times 10^{6}, \mathrm{H}\right)$, medium number $\left(1 \times 10^{5}\right.$, $\mathrm{M})$, and low number $\left(1 \times 10^{4}, \mathrm{~L}\right)$ of grafts, respectively (Additional file 2: Figure S2). The survival curves of each group of the seven mouse strains are shown in Fig. 1. The median survival time was 19 days in NSI mice, 21 days in NOD-scid mice, 23 days in scid mice, and 45 days in IL2Rg-/- mice when $1 \times 10^{6} \mathrm{~K} 562$-GFP cells were injected (Fig. 1a). No K562 cells were detected in WT mice after transplantation (Fig. 1a). After the injection of $1 \times 10^{5}$ K562-GFP cells, successful reconstitution of leukemia was observed in NSI (medium survival time 27 days) and NOD-scid (medium survival time 48 days) mice (Fig. 1b), but not in IL2Rg-/-, scid, Rag2-/-, nude, or WT mice. The injection of $1 \times 10^{4}$ K562-GFP cells reconstituted leukemia in the NSI mice, whereas leukemia cells were under detectable in NOD-scid, IL2Rg-/-, scid, Rag2-/-, nude, or WT mice (Fig. 1c). Because K562 cells were not detected in the bone marrow (BM) or spleen (SP) of the seven strains tested, we then measured the percentages of K562 cells in the peripheral blood (PB) of each mouse and found that the engraftment efficiencies were highest in the NSI mice, followed by the NOD-scid, IL2Rg-/-, scid, Rag2-/-, and nude mice, in that order (Fig. 1d).

Similarly, we measured the immunodeficiency of the seven strains for hematologic allografts by injecting RMA-GFP cells [27], which continuously expressed GFP (Additional file 1: Figure S1 and Additional file 2: Figure S2). The lifespan of each strain after tumor transplantation increased in the sequential order of NSI, IL2Rg-/-, NODscid, scid, Rag2-/-, nude, and WT after $1 \times 10^{6}$ RMA-GFP cells were injected (Fig. 2a). The injection of $1 \times 10^{5}$ RMA-GFP cells did not reconstitute tumors in WT mice (Fig. 2b). After the injection of $1 \times 10^{4}$ RMA-GFP cells, successful engraftments were detected in only NSI, IL2Rg-/-, and NOD-scid mice (Fig. 2c). We measured the percentages of RMA-GFP in the PB (Fig. 2d), SP (Fig. 2e), and BM (Fig. 2f) of each mouse.

\section{Assessing the ability to prevent the engraftment of solid tumor}

To evaluate the feasibility of the seven mouse strains for solid tumor xenografts, we measured the immunodeficiency of a mouse strain by testing its ability to prevent solid tumor engraftment. We subcutaneously injected the six immunodeficient mouse strains and WT mice with A549 cells (for xenografts), a human adenocarcinoma alveolar basal epithelial cell line [28], or B16F10 cells (for allografts), which are a murine skin melanoma [29], to assess the tumor mass. Three groups of mice (five mice per 


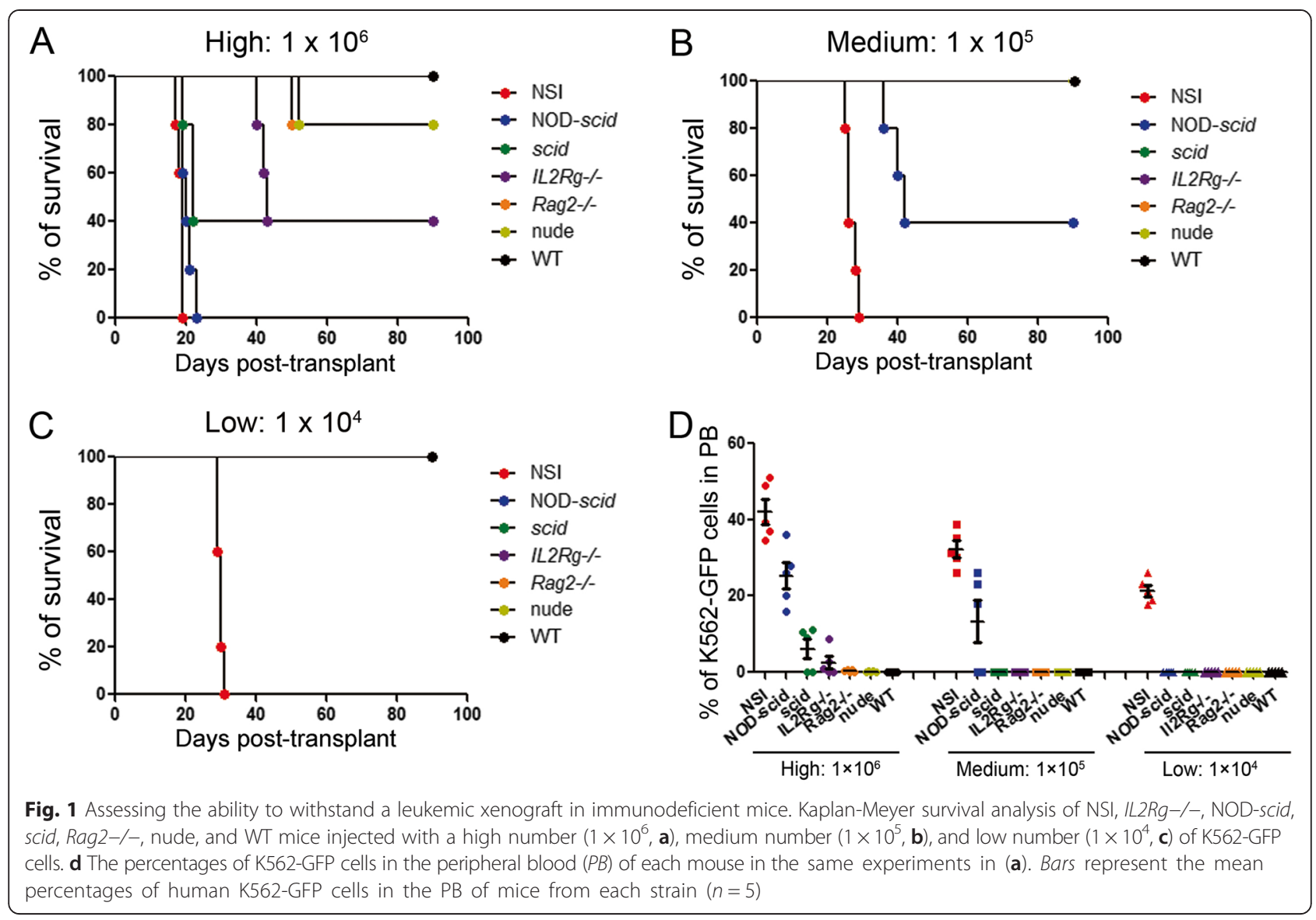

group) were assayed with a high number $\left(1 \times 10^{6}, \mathrm{H}\right)$, medium number $\left(1 \times 10^{5}, \mathrm{M}\right)$, and low number $\left(1 \times 10^{4}, \mathrm{~L}\right)$ of grafts, respectively (Additional file 2: Figure S2). Twenty days (for allografts) or 30 days (for xenografts) after transplantation, the engraftment efficiencies of the tumor cells were determined by measuring the mass of the tumor under the skin.

Notably, we found that $1 \times 10^{4}$ A549 cells were able to form tumors in the NSI mice, whereas $1 \times 10^{5}$ A549 cells were required for successful engraftments in the NODscid, scid, and nude mice (Fig. 3a). However, $1 \times 10^{6}$ A549 cells were needed to induce tumorigenesis in Rag2-/and IL2Rg-/- mice. No tumors were observed in WT mice (Fig. 3a). Similarly, we measured the immunodeficiency of the seven strains for allografts by injecting B16F10 cells into five mice of each strain (Additional file 2: Figure S2). Consistent with the A549 xenograft results, tumors were detected in NSI mice after the injection of as few as $1 \times 10^{4}$ B16F10 cells (Fig. 3b). The weights of the tumors increased in the sequential order of WT, nude, IL2Rg-/-, scid, Rag2-/-, NOD-scid, and NSI mice after the injection of $1 \times 10^{5}$ or $1 \times 10^{6}$ B16F10 cells (Fig. 3b).

\section{Formula to quantify the immunodeficiency of the} immunodeficient mice

The capacities of both hematologic and solid tumor induction in the seven mouse strains evaluated suggested that the immunodeficiency was positively correlated with the capacity for tumor engraftment, which was also supported by previous studies $[22,23]$. To quantify the immunodeficiency of a specific mouse strain, we developed a tumor engraftment index (TEI) that is negatively correlated to its capacity to prevent the development of non-self tumor cells. For a given time of death, TEI is proportional to the engraftment efficiency. However, for a given engraftment efficiency, TEI is inversely proportional to the time of death of the mice injected with tumor. For example, the TEI of WT or normal mice having a healthy immune system was zero; the TEI of mice with a severely impaired immune system was substantially higher. Therefore, we propose that the TEI of an individual mouse can be calculated by dividing its tumor engraftment by its lifespan after injection with the tumor cells. The quantification of tumor engraftments varies between hematologic tumors and solid tumors.

For the hematologic tumor engraftment index, $I_{\text {strain-hematologic tumor- } n}=\frac{\mathrm{Gi}}{\mathrm{Di}}$ where "strain" is the name of 


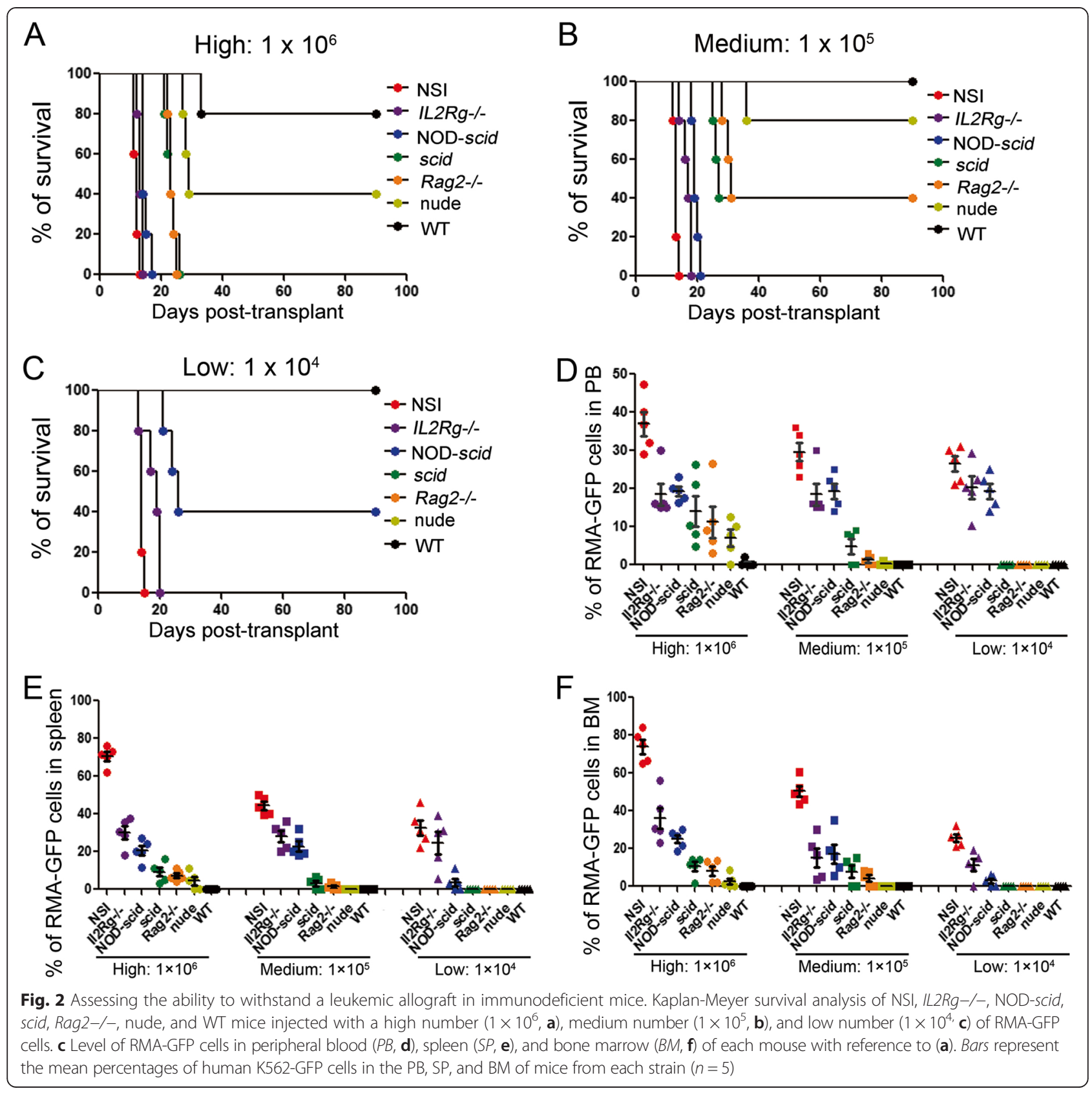

the immunodeficient mice; "hematologic tumor" is the name of the tumor cells; $n$ denotes the number of individuals; "Gi" is the sum of the percentages of tumor cells in the peripheral blood $\left(G_{\mathrm{PB}}\right)$, bone marrow $\left(G_{\mathrm{BM}}\right)$, and spleen $\left(G_{\mathrm{SP}}\right)$ of an individual mouse when the mouse is morbid or killed; and "Di" is the lifespan of the individual mouse after injection of the tumor cells.

For the solid tumor engraftment index, $I_{\text {strain-solid tumor }-n}=\frac{\mathrm{Wi}}{D}$ where "strain" is the name of the immunodeficient mice, "solid tumor" is the type of tumor cells for transplantation, $n$ denotes the number of individuals, "Wi" is the weight of the graft in the mouse when the mouse is morbid or killed, and $D$ is the survival time of the mouse after injection of the tumor.

The final score of the TEI is the average of In of hematologic and solid tumors:

$$
\begin{aligned}
& I_{\text {strain-allograft- } n}=\left(I_{\text {strain-RMA- } n}+I_{\text {strain-B16F10-n }}\right) / 2 \\
& I_{\text {strain-xenograft-n }}=\left(I_{\text {strain-k562-n }}+I_{\text {strain-A549-n }}\right) / 2
\end{aligned}
$$

To improve the convenience of calculation of TEI scores, we designed the website (http://www.nsitei.com) 


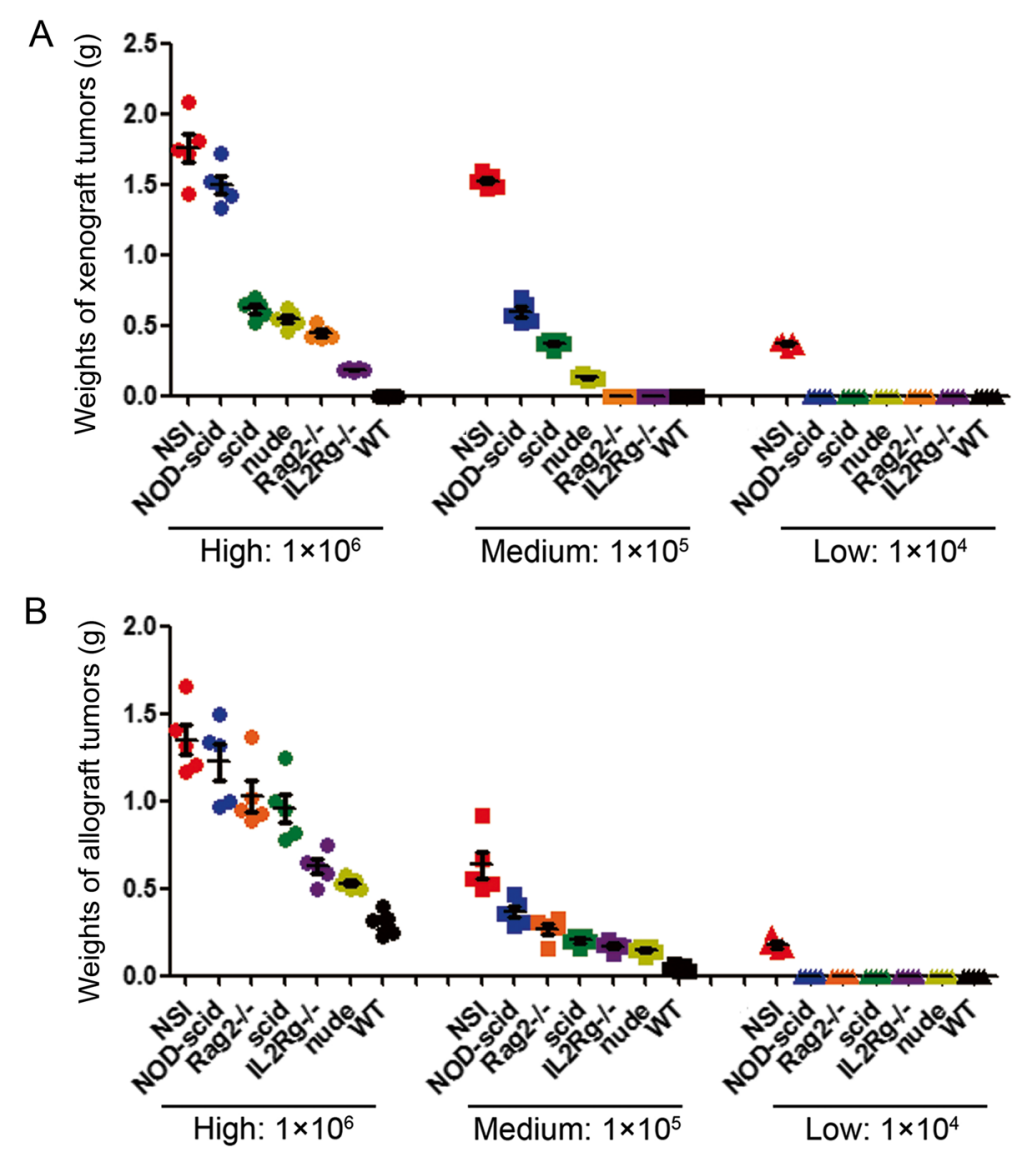

Fig. 3 Assessing the ability to withstand a solid tumor in immunodeficient mice. The weight of the solid xenografts (a) and allografts (b) in NSI, IL2Rg-/-, NOD-scid, scid, Rag2-/-, nude, and WT mice transplanted with a high number $\left(1 \times 10^{6}\right)$, medium number $\left(1 \times 10^{5}\right)$, and low number $\left(1 \times 10^{4}\right)$ of A549 or B16F10. Bars represent the mean weight of grafts from mice of each strain $(n=5)$

based on the TEI equation in Table 1 . According to the TEI equation, we calculated the TEI scores for each strain (Additional file 3: Table S1 and Additional file 4: Table S2) and found that NSI mice had the highest TEI scores in both the xenograft and allograft tests, followed by scid, nude, and WT mice. Interestingly, the allograft TEI scores of IL2Rg-/- were higher than those of NODscid and scid mice (Fig. 4a), whereas IL2Rg-/- had lower TEI scores than NOD-scid and scid mice in the xenograft tests (Fig. 4b). The recent observations of greater leukemogenic engraftment in NSG mice than in NODscid mice [22], and of the greater susceptibility to tumor formation of NOG mice than nude and scid mice [23], indicated that the TEI scoring system provides an efficient method to assess the tumor engraftment efficiency of immunodeficient mice.

\section{Hematopoietic functional assay in NSI mice}

We then used three types of functional assay to validate whether NSI mice were more suitable for xenograft than NOD-scid mice, as suggested by the TEI results. First, we compared the human hematopoietic engraftment capacities of the NSI mice and NOD-scid mice by engrafting the sub-lethally irradiated mice with $1 \times 10^{4}$ and $1 \times 10^{5}$ of human umbilical cord blood CD34+ cells, respectively. Twelve weeks after the transplantations, the percentages of human CD45+ cells in the PB, SP, and BM of the NSI mice were significantly higher than those of the NOD-scid mice (Fig. 5a). Furthermore, the injected human CD34+ cells differentiated into multiple hematopoietic lineages, including B cells, T cells, and myeloid cells (Fig. 5b).

Second, we examined whether human hematopoietic progenitors were able to reconstitute a functional immune system in NSI mice. We established a humanized BLT mouse model by surgically implanting human thymus and liver fragments into kidney capsules and injecting donor-matched human hematopoietic stem/progenitor cells $\left(\mathrm{CD} 34^{+}\right)$intravenously into NSI mice (Additional file 5: Figure S3). Twelve weeks after transplantation, we analyzed the immune system in the recipient BLT-NSI mice. We found human mature CD4+ and CD8+ T cells, CD19+ immunoglobulin (Ig)M+ mature B cells, CD56+ NK cells, and CD14/33+ monocytes/macrophages in the BLT-NSI mice (Fig. 5c). More importantly, we detected 
Table 1 Equation for calculating TEl scores

TEl score for RMA

\begin{tabular}{|c|c|c|c|c|c|c|c|c|c|c|c|c|c|c|c|c|c|}
\hline \multirow[t]{2}{*}{ Mouse number } & \multicolumn{4}{|l|}{$\mathrm{H}$} & \multicolumn{4}{|l|}{$M$} & \multicolumn{4}{|l|}{$\mathrm{L}$} & \multirow{2}{*}{$\begin{array}{l}\mathrm{TE}_{H} \\
\left(G_{\mathrm{PB}}+G_{\mathrm{SP}}+G_{\mathrm{BM}}\right) / D\end{array}$} & \multirow{2}{*}{$\begin{array}{l}\mathrm{TE}_{\mathrm{M}} \\
\left(G_{\mathrm{PB}}+G_{\mathrm{SP}}+G_{\mathrm{BM}}\right) / D\end{array}$} & \multirow{2}{*}{$\begin{array}{l}T E_{L} \\
\left(G_{\mathrm{PPB}}+G_{S P}+G_{B M}\right) / D\end{array}$} & \multirow{2}{*}{$\begin{array}{l}T E I_{R M A} \\
\left(\left.T E\right|_{H}+T E I_{M}+\left.T E\right|_{\llcorner}\right) / 3\end{array}$} & \multirow{2}{*}{$\begin{array}{l}\text { Average } \\
\text { of TE }\left.\right|_{R M}\end{array}$} \\
\hline & $G_{P B}$ & $G_{S P}$ & $G_{B M}$ & $D$ & $G_{P B}$ & $G_{S P}$ & $G_{B M}$ & $D$ & $G_{P B}$ & $G_{S P}$ & $G_{B M}$ & D & & & & & \\
\hline 1 & 0 & 0 & 0 & 1 & 0 & 0 & 0 & 1 & 0 & 0 & 0 & 1 & 0 & 0 & 0 & 0 & 0 \\
\hline 2 & 0 & 0 & 0 & 1 & 0 & 0 & 0 & 1 & 0 & 0 & 0 & 1 & 0 & 0 & 0 & 0 & \\
\hline 3 & 0 & 0 & 0 & 1 & 0 & 0 & 0 & 1 & 0 & 0 & 0 & 1 & 0 & 0 & 0 & 0 & \\
\hline 4 & 0 & 0 & 0 & 1 & 0 & 0 & 0 & 1 & 0 & 0 & 0 & 1 & 0 & 0 & 0 & 0 & \\
\hline 5 & 0 & 0 & 0 & 1 & 0 & 0 & 0 & 1 & 0 & 0 & 0 & 1 & 0 & 0 & 0 & 0 & \\
\hline
\end{tabular}

TEl score for B16F10

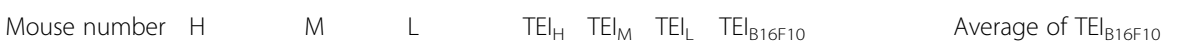

\begin{tabular}{|c|c|c|c|c|c|c|c|c|c|c|c|c|c|c|c|c|c|}
\hline & W & $D$ & w & $D$ & w & D & $G / D$ & $G / D$ & $G / D$ & $\left(\left.T E\right|_{H}+\left.T E\right|_{M}+T E I_{L}\right) / 3$ & & & & & & & \\
\hline 1 & 0 & 1 & 0 & 1 & 0 & 1 & 0 & 0 & 0 & 0 & 0 & & & & & & \\
\hline 2 & 0 & 1 & 0 & 1 & 0 & 1 & 0 & 0 & 0 & 0 & & & & & & & \\
\hline 3 & 0 & 1 & 0 & 1 & 0 & 1 & 0 & 0 & 0 & 0 & & & & & & & \\
\hline 4 & 0 & 1 & 0 & 1 & 0 & 1 & 0 & 0 & 0 & 0 & & & & & & & \\
\hline 5 & 0 & 1 & 0 & 1 & 0 & 1 & 0 & 0 & 0 & 0 & & & & & & & \\
\hline$T^{\left.T E\right|_{\text {allograft }}}$ & 0 & & & & & & & & & & & & & & & & \\
\hline \multicolumn{18}{|c|}{ TEl score for K562 } \\
\hline \multirow[t]{2}{*}{ Mouse number } & $\mathrm{H}$ & & & & M & & & & L & & & & $\mathrm{TE}_{\mathrm{H}}$ & $T E I_{M}$ & $\mathrm{TEL}_{\mathrm{L}}$ & $\mathrm{TE}_{\mathrm{K} 562}$ & \multirow{2}{*}{$\begin{array}{l}\text { Average } \\
\text { of TEI }\left.\right|_{562}\end{array}$} \\
\hline & $G_{P B}$ & $G_{\mathrm{SP}}$ & $G_{B M}$ & $D$ & $G_{P B}$ & $G_{S P}$ & $G_{B M}$ & $D$ & $G_{P B}$ & $G_{S P}$ & $G_{B M}$ & $D$ & $\left(G_{\mathrm{PB}}+G_{\mathrm{SP}}+G_{\mathrm{BM}}\right) / D$ & $\left(G_{P B}+G_{S P}+G_{B M}\right) / D$ & $\left(G_{\mathrm{PPB}}+G_{\mathrm{SP}}+G_{\mathrm{BM}}\right) / D$ & $\left(\left(\left.T E\right|_{H}+\left.T E\right|_{M}+T E I_{L}\right) / 3\right)$ & \\
\hline 1 & 0 & 0 & 0 & 1 & 0 & 0 & 0 & 1 & 0 & 0 & 0 & 1 & 0 & 0 & 0 & 0 & \multirow[t]{5}{*}{0} \\
\hline 2 & 0 & 0 & 0 & 1 & 0 & 0 & 0 & 1 & 0 & 0 & 0 & 1 & 0 & 0 & 0 & 0 & \\
\hline 3 & 0 & 0 & 0 & 1 & 0 & 0 & 0 & 1 & 0 & 0 & 0 & 1 & 0 & 0 & 0 & 0 & \\
\hline 4 & 0 & 0 & 0 & 1 & 0 & 0 & 0 & 1 & 0 & 0 & 0 & 1 & 0 & 0 & 0 & 0 & \\
\hline 5 & 0 & 0 & 0 & 1 & 0 & 0 & 0 & 1 & 0 & 0 & 0 & 1 & 0 & 0 & 0 & 0 & \\
\hline
\end{tabular}

TEl score for A549

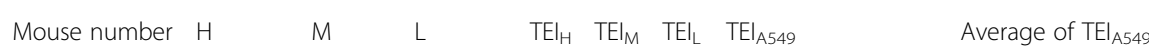

\begin{tabular}{lllllllllll} 
& $W$ & $D$ & $W$ & $D$ & $W$ & $D$ & $G / D$ & $G / D$ & $G / D$ & $\left(\left.T E\right|_{H}+\left.T E\right|_{M}+\left.T E\right|_{L}\right) / 3$ \\
\hline 1 & 0 & 1 & 0 & 1 & 0 & 1 & 0 & 0 & 0 & 0
\end{tabular}

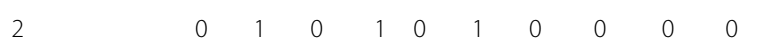

$\begin{array}{lllllllllll}3 & 0 & 1 & 0 & 1 & 0 & 1 & 0 & 0 & 0 & 0\end{array}$

$4 \quad \begin{array}{llllllllll}0 & 1 & 0 & 1 & 0 & 1 & 0 & 0 & 0 & 0\end{array}$

TEl xenograft

aFill the RMA-GFP engraftment efficiency in PB, SP, BM $\left(G_{P B}, G_{S P}, G_{B M}\right)$, and survival day $(D)$ transplanted with $H, M$, and $L$ of cells in table "TEl score for RMA"

${ }^{\mathrm{b}}$ Fill the tumor weight of B16F10 $(\mathrm{W})$ and sacrificed day $(D=20)$ transplanted with $\mathrm{H}, \mathrm{M}$, and $\mathrm{L}$ of cells in table "TEl score for B16F10"

"Fill the K562-GFP engraftment efficiency in PB, SP, and BM $\left(G_{\mathrm{PB}}, G_{\mathrm{SP}}, G_{\mathrm{B}}\right)$, and survival day $(D)$ transplanted with $\mathrm{H}, \mathrm{M}$, and $\mathrm{L}$ cells in table "TEl score for K562"

${ }^{d}$ Fill the tumor weight of $A 549(W)$ and sacrificed day $(D=30)$ transplanted with $H, M$, and $L$ of cells in table "TEl score for $A 549$ " 

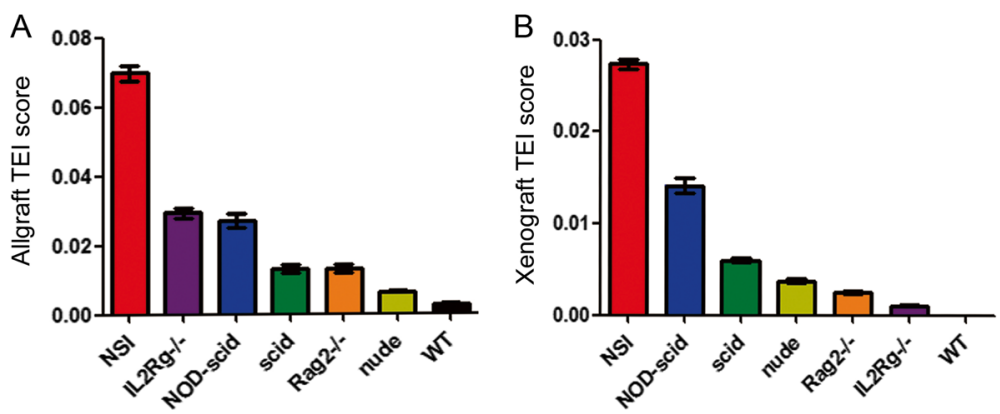

Fig. 4 Final TEl score. Summary of the final TEl score of NSI, IL2Rg-/-, NOD-scid, scid, Rag2-/-, nude, and WT mice in the allograft (a) and xenograft (b) assay

not only human IgG in the sera of the BLT-NSI mice but also ovalbumin (OVA)-specific human IgG from the sera of the mice after they were immunized with OVA peptides (Fig. 5d). Conversely, we failed to reconstitute functional human immune systems in the NOD-scid mice using the same method (data not shown).

Finally, we tested whether a single human primary leukemic cell was capable of reconstituting leukemia in NSI mice. Twenty weeks after the transplantation of a single primary B-ALL cell, human CD45 $5^{+}$B-ALL was reconstituted in the NSI mice, but not in the NOD-scid mice (Fig. 5e).

\section{Establishment of solid tumor patient-derived xenografts with NSI mice}

We further examined whether NSI mice were suitable for modeling solid tumor patient-derived xenograft (PDX). Ten primary non-small cell lung cancer (NSCLC) samples from different patients were harvested and implanted subcutaneously into NSI mice (Table 2). Six of the 10 samples were successfully engrafted in NSI mice (Table 2). Therefore, the successful rate of modeling NSCLC in PDX using NSI mice was $60 \%$, which was higher than the $24.5 \%$ in NOD-scid mice [30,31] and $35 \%$ in scid mice [32]. Interestingly, we detected murine $\mathrm{Ly} 6 \mathrm{~g}+\mathrm{CD} 11 \mathrm{~b}+$ macrophages in the tumors from the NSCLC PDX models (Additional file 6: Figure S4). The tumors in the NSCLC PDX models exhibited similar morphology to that of the patient tissues from which the primary models were derived (Fig. 6). In addition, dissociated tumor cells from primary lung cancer samples were also able to reconstitute tumors with similar morphology to that of the patient tumors (Additional file 7: Figure S5).

\section{Discussion}

Several strains of immunodeficient mice are available for basic and translational research, including BALB/c nude (nude), scid, NOD-scid, IL2Rg-/-, Rag2-/-, and NODscid-IL2Rg-/- mice. However, the choice of an appropriate immunodeficient mouse strain is difficult, because a standardized system to evaluate the immunodeficiency of mice is lacking. In this study, we proposed an index, the TEI, to represent the capacity of a mouse strain to enhance or prevent the expansion of foreign cells in vivo. We then developed a TEI scoring method to quantitatively assess the growth of tumor cell lines in different immunodeficient mouse strains. Multiple functional assays were used to validate the correlation between the immunodeficiency of a mouse strain and its TEI score. The final TEI scores of tested immunodeficient strains are helpful to select appropriate immunodeficient strains for different experiments. For example, NSI and $I L 2 R g-/-$ strains are more suitable for allograft studies, while NSI and NODscid strains are preferred for establishing xenografts. Thus, the TEI scoring system was shown to be a practical and convenient method to quantify the immunodeficiency of a mouse strain. It is interesting to notice that IL2Rg-/mice exhibited the seemingly paradoxical TEI scores in allograft and xenograft tests. Due to different genetic mutations in NSI, NOD-scid, and IL2Rg-/- strains, development and activities of adaptive and innate immunities, including B cells, T cells, NK cells, and macrophages, are different among these strains. In addition, NK cells and $\mathrm{T}$ cells use different machinery to recognize tumors in both allografts and xenografts. Therefore, the different compartments of immune systems in these strains and the genetic background of tumor cells used in allografts and xenografts may explain the paradoxical TEI scores of $I L 2 R g-/-$ strain in allograft and xenograft tests.

The immune system not only prevents tumor growth but also attacks other non-self entities, such as viruses, fungi, and bacteria [33]. However, immune system responds to various bacterial, viral, fungal in association with toll-like receptors and much unknown innate receptors $[33,34]$ Thus, the TEI scoring method that only uses cancer cells for an evaluation cannot assess the immunodeficiency of a mouse strain comprehensively. In addition, it is not practical for an ordinary laboratory to use viruses or bacteria to measure the immunodeficiency of certain mouse strains, because most of the immunodeficient strains are maintained in specific pathogen-free 
A

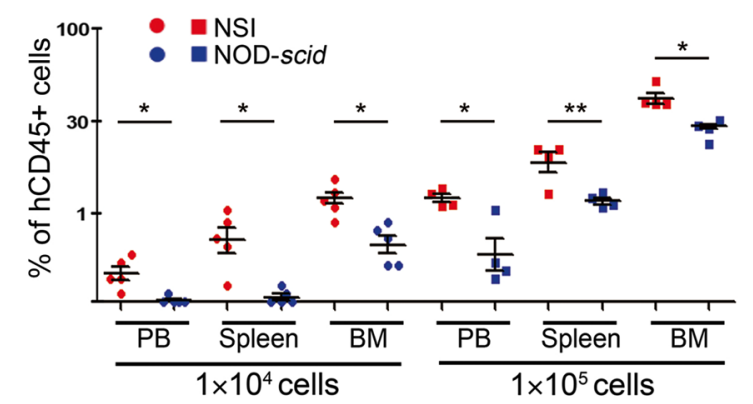

B

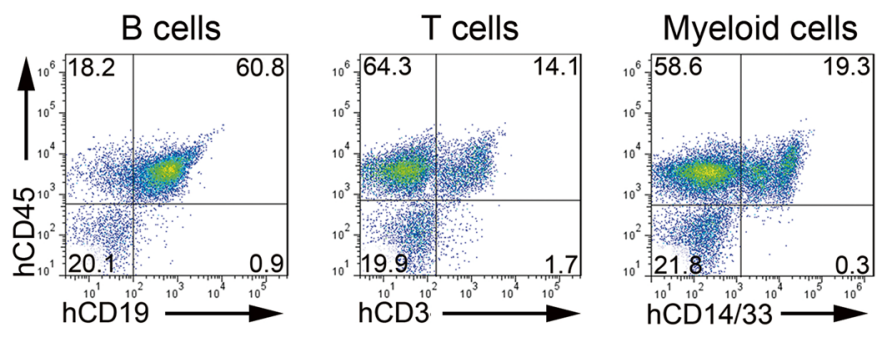

C
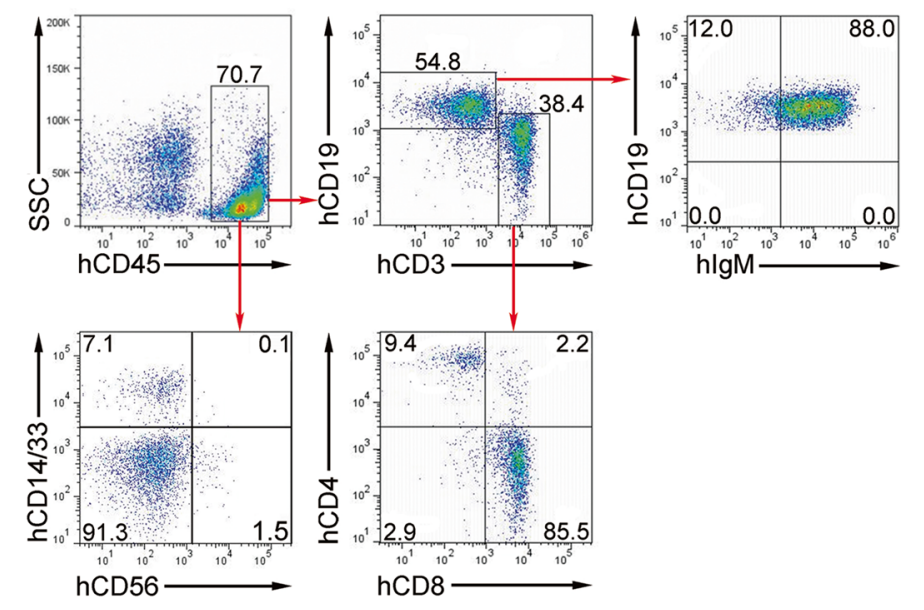

D

Total $\lg G$

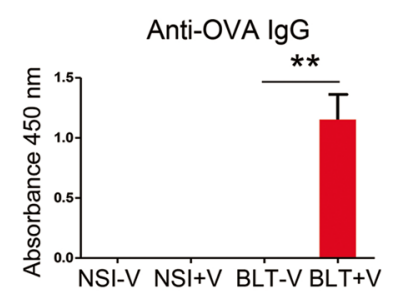

E
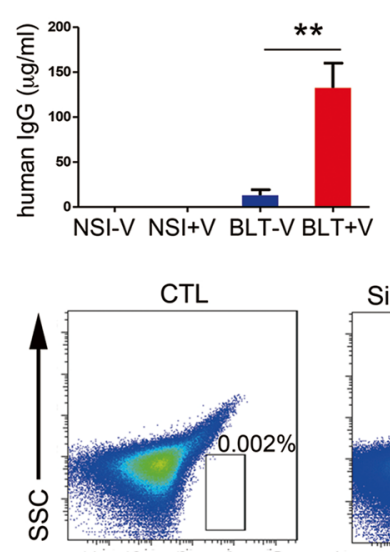

Single B-ALL cell

Fig. 5 (See legend on next page.)

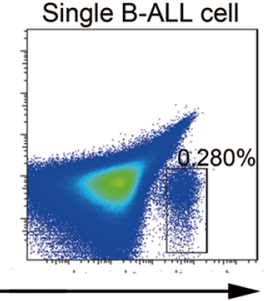

hCD45 
(See figure on previous page.)

Fig. 5 Hematopoietic functional assays of NSI mice. a Summary of percentages of human CD45+ cells in the PB, BM, and SP of NSI (red plot) and NOD-scid (blue plot) mice 20 weeks after injection with $1 \times 10^{4}$ or $1 \times 10^{5}$ purified human CD34+. Bars represent the mean percentages of human CD $45+$ cells in the PB, BM, and SP of mice from each group ( $n=4$ or 5 per group). ${ }^{*} P \leq 0.05$ for bar 1 versus bar 2 , bar 3 versus bar 4 , bar 5 versus bar 6 , bar 7 versus bar 8 , and bar 11 versus bar $12 ;{ }^{*} P \leq 0.01$ for bar 9 versus bar 10. b Representative FACS analysis of percentages of multiple hematopoietic lineages in NSI as described in (a). c Representative fluorescence-activated cell sorting (FACS) analysis of percentages of multiple hematopoietic lineages in NSI transplanted with human cord blood CD34+/liver/thymus. $\mathbf{d}$ The level of human lgG (left) and OVA-specific lgG (right) in serum of NSI mice transplanted with human cord blood CD34+/liver/thymus. Open bars represent NSI mice that received human cord blood CD34+/liver/thymus $(n=3)$. Data are represented as the mean \pm standard error of the mean. ${ }^{* *} P \leq 0.01$ for bar 3 versus bar 4 and bar 7 versus bar 8. e Representative FACS analysis of percentages of human CD45+ cells in NSI (right) and Nod-scid (left) transplanted with a single primary B-ALL cell

grade animal facilities. Therefore, the current TEI scoring method is more suitable for oncologists than microbiologists. To evaluate immunodeficiency more comprehensively and accurately, more parameters need to be incorporated into the TEI scoring system, including the ability to defend against bacterial or viral infections.

\section{Conclusions}

Due to its simplicity and accuracy, the TEI can be used widely to help researchers to decide which strain is most suitable for their xenograft experiments. In addition, the TEI scoring system may be used to evaluate at least partially the immunodeficiency of genetically modified mice and other species in oncologic studies in the future.

\section{Material and methods}

\section{Mice}

Animal experiments were performed in the Laboratory Animal Center of the Guangzhou Institutes of Biomedicine and Health (GIBH), and all animal procedures were approved by the Animal Welfare and Ethical Committee of GIBH (the ethical process number: N2014050). IL2Rg-/mice were purchased from Jackson Laboratories. NODscid, scid, nude, and WT mice were purchased from Vital River Laboratory Animal Technology Co. (Beijing). Rag2-/- mice were purchased from HFK Bioscience Co.
(Beijing). We generated NOD-scid-IL2Rg-/- by TALENmediated gene targeting in the NOD background and named the new strain of immunodeficient mice NSI. The absence of $\mathrm{T}, \mathrm{B}$, and NK cells in the PB, SP, and BM of NSI mice was determined by Accuri ${ }^{\mathrm{Tm}}$ C6 (BD Biosciences, San Jose, CA, USA). All of the mice were bred and maintained in specific pathogen-free grade cages and provided with autoclaved food and water.

\section{Cell culture}

RMA cells were obtained from Professor Pengtao Liu (Sanger Institute, Cambridge, UK), and K562 cells were obtained from the American Type Culture Collection (ATCC, Manassas, VA, USA). RMA, A549, and B16F10 cells were maintained in RPMI-1640 medium (Gibco, New York, NY, USA) with $10 \%$ fetal bovine serum (FBS; Biochrom, Australia). K562 cells were maintained in Iscove's Modified Dulbecco Medium (Thermo Scientific, MA, USA) with 10 $\%$ FBS. The 293T cells used for lentivirus packaging were kindly provided by Professor Duanqing Pei (GIBH) and maintained in Dulbecco's Modified Eagle's medium (Gibco, New York, NY, USA) with 10 \% FBS. All primary samples were obtained with informed consent for research purposes, and the procedures were approved by the Research Ethics Board of the GIBH. All cells were cultured at $37^{\circ} \mathrm{C}$ in $5 \%$ carbon dioxide and a normal level of oxygen.

Table 2 Information of patients and corresponding patient-derived xenograft mouse models

\begin{tabular}{|c|c|c|c|c|c|c|c|}
\hline Number & Gender & Age & EGFR mutation & Pathology & Stage & TNM stage & Engrafted \\
\hline 1 & M & 60 & WT & $A C$ & IB & T2NOMO & Yes \\
\hline 2 & M & 69 & WT & $A C$ & $\| \mathrm{A}$ & T2N1M0 & Yes \\
\hline 3 & M & 65 & WT & $A C$ & IA & T2NOM1 & Yes \\
\hline 4 & M & 67 & WT & LCC & IA & T2N1M0 & Yes \\
\hline 5 & $\mathrm{~F}$ & 69 & G719X/exon 19 del & $A C$ & $\| \mathrm{B}$ & T2N1M0 & No \\
\hline 6 & M & 62 & WT & $A C$ & IV & T2NOMO & No \\
\hline 7 & M & 71 & WT & SCC & IB & T2NOMO & Yes \\
\hline 8 & M & 62 & WT & $A C$ & $\| \mathrm{A}$ & $\mathrm{T} 2 \mathrm{~N} 2 \mathrm{MO}$ & No \\
\hline 9 & $\mathrm{~F}$ & 40 & Exon 19 del & $A C$ & IV & T2N1M0 & Yes \\
\hline 10 & M & 67 & L858R & SCC & IB & T2N0MO & No \\
\hline
\end{tabular}

$M$ male, $F$ female, $A C$ adenocarcinoma, $L C C$ large cell carcinoma, SCC squamous cell carcinoma 


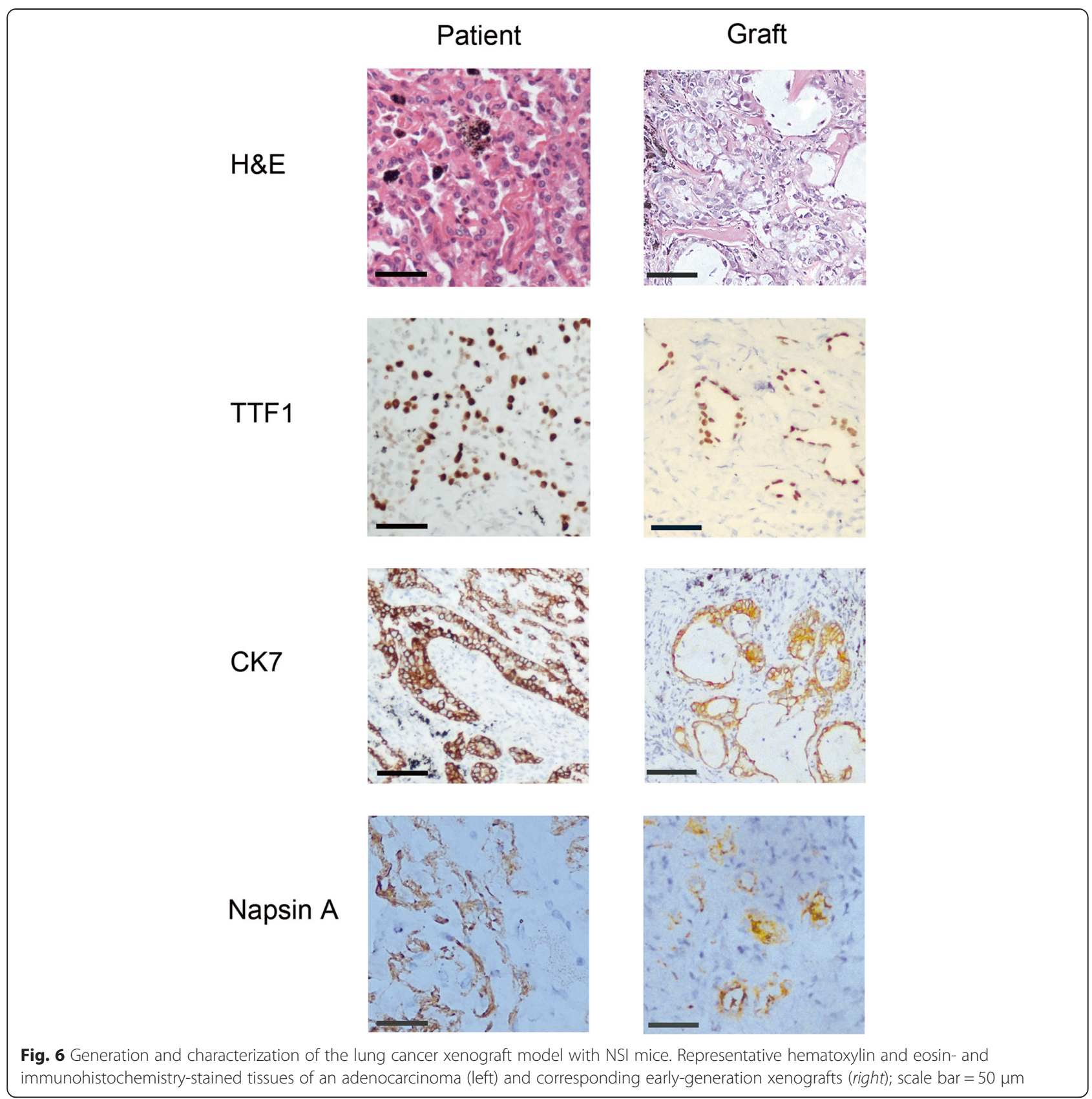

\section{Lentivirus production and transduction}

Twenty-four hours before the transfection, the HEK293T cells in logarithmic growth phase were trypsinized, and the cell density was adjusted to $1.0 \times 10^{6}$ cells $/ \mathrm{mL}$ with complete culture medium. The cells were reseeded into $15-\mathrm{cm}$ cell culture dishes and cultured for $24 \mathrm{~h}$ before transfection. When the cells were 90-95\% confluent on the day of transfection, the recombinant viral vector encoding GFP and the two packaging plasmids psPAX2 and pMD2.G were co-transfected into the HEK-293T cells using Lipofectamine 2000 (Invitrogen, New York, NY, USA) according to the manufacturer's instructions. At
$48 \mathrm{~h}$ after transfection, the culture medium was collected and centrifuged at $4000 \times g$ at $4{ }^{\circ} \mathrm{C}$ for $10 \mathrm{~min}$ to remove any cellular debris. The supernatant was filtered through a $0.45-\mu \mathrm{m}$ filter and collected to transfect the RMA and K562 cells. The RMA-GFP+ and K562-GFP+ cells were sorted out using FACSAria ${ }^{\mathrm{Tm}}$ II (Becton Dickinson, San Jose, CA, USA) for culture.

\section{Flow cytometry analysis}

Cells were isolated from the PB, BM, and SP for flow cytometric analyses. To analyze the human and mouse cells, the cells were labeled with anti-hCD3-fluorescein 
isothiocyanate, anti-hCD4-allophycocyanin (APC), antihCD8a-peroxidase (PE), anti-hCD14-PE, anti-hCD33PE, anti-hCD71-PE, anti-hCD56-APC, anti-hIgM-eFluor 450, anti-hCD45-Percp Cy 5.5, anti-mCD4-PE, anti-mCD8peridinin chlorophyll (Percp) Cy 5.5, anti-mCD19-APC, anti-mB220-Percp, anti-mCD3-APC, anti-mNKp46-PE, anti-mCD71-PE, anti-m TER119-APC, anti-mCD11b-PE, and anti-mGr-1-APC. All of the antibodies were obtained from eBioscience (San Diego, CA, USA) unless specifically stated. Flow cytometric analysis was performed using Accuri C6 or FACSAria ${ }^{\text {tw }}$ II. All of the data were analyzed with FlowJo software (Tree Star, Inc., Ashland, OR, USA).

\section{Engraftments of leukemia and solid tumors}

For a direct comparison of susceptibility to cancer cell engraftment, $1 \times 10^{4}(\mathrm{~L}), 1 \times 10^{5}(\mathrm{M})$, or $1 \times 10^{6}(\mathrm{H})$ of RMAGFP+, K562-GFP+, A549, or B16F10 cells suspended in $0.2 \mathrm{~mL}$ of phosphate buffer solution were injected into the tail vein of five NSI, IL2Rg-/-, NOD-scid, scid, nude, and WT mice. Similarly, $1 \times 10^{4}(\mathrm{~L}), 1 \times 10^{5}(\mathrm{M})$, or $1 \times 10^{6}$ (H) of A549 or B16F10 cells suspended in $0.2 \mathrm{~mL}$ of phosphate buffer solution were injected subcutaneously into five NSI, IL2Rg-/-, NOD-scid, scid, nude, and WT mice. The end points proposed were based on animal models in widespread use [35]. The engraftment of leukemia was measured by analyzing the GFP+ cells in the PB every week or when the mice were moribund at a maximum of 90 days after grafting. Due to regulations of research animal welfare, we terminated the mice once the diameters of their tumor reach $1.2 \mathrm{~cm}$. 1B16F10 and A549 cells took 20 and 30 days, respectively, to develop into a $1.2-\mathrm{cm}$ tumor in NSI mice.

\section{Reconstitution of human hematopoiesis in NSI mice}

The human cord blood was collected at the South China Medical University (SCMU) Department of Gynecology and Obstetrics with informed consent for research purposes only, and this process was monitored by the Institutional Review Boards of the SCMU. Human cord whole white blood cells were isolated using Lymphoprep (Stemcell Technologies, Canada) according to the manufacturer's instructions. Human cord blood CD34+ cells were enriched via magnetic cell sorting (Miltenyi, Bergisch Gladbach, Germany). A total of $1 \times 10^{4}$ or $1 \times 10^{5}$ uncultured human CD34+ cells were pooled together and injected intravenously via the retro-orbital route into sub-lethally irradiated (1.5 Gy) 8-10-week-old NSI mice. After 12 weeks, the mice were killed, and the bone marrow from femurs was analyzed by flow cytometry for the presence of human CD45+ and blood lineage cells. In our engraftment assay, the mice were considered to have been engrafted successfully when $\geq 0.1 \%$ human $\mathrm{CD} 45+$ cells were detected in the bone marrow 8 weeks after transplant.

\section{BLT mice}

Human fetal thymus and liver tissues were obtained from the SCMU. Human fetal thymus and liver fragments measuring about $2 \mathrm{~mm}^{3}$ were implanted under the renal capsule of sub-lethally irradiated NSI mice. The mice also received CD34+ cells $\left(5 \times 10^{5} /\right.$ mouse, intravenously) purified from the same donor on the day of human thymus/ liver transplantation. After 12 weeks, PBMCs from the recipient mice were analyzed by flow cytometry for the presence of human CD45+ and blood lineage cells.

\section{Single-cell preparation}

PBMCs were collected from B-ALL patients (SCMU Department of Gynecology). To remove the red blood cells, the cells were treated with $1 \times \mathrm{RBC}$ lysis buffer (eBioscience) according to the manufacturer's instructions. To isolate a single cell from the B-ALL patients' peripheral blood, single-cell suspensions were prepared by standard procedures. The single cell was then transplanted into NSI mice.

\section{Enzyme-linked immunosorbent assay}

The human Ig concentration in recipient serum was measured by using a human Ig assay kit (ab100547, Abcam, Cambridge, UK). To detect OVA-specific human IgG antibodies, five recipient BLT mice were immunized twice every 2 weeks with $100 \mu \mathrm{g}$ of OVA (Sigma, St Louis, MO, USA) that was emulsified in aluminum hydroxide (Sigma). OVA was plated at a concentration of $10 \mu \mathrm{g} / \mathrm{mL}$ in 96-microtiter wells at $4{ }^{\circ} \mathrm{C}$ overnight. After washing and blocking with bovine serum albumin, the serum samples were incubated in the plate for $1 \mathrm{~h}$. Antibodies binding OVA were then measured by a standard enzymelinked immunosorbent assay.

\section{Establishment of xenografts}

Surgical tumor samples were obtained from the Sun Yat-Sen University Cancer Center (Guangzhou, China), and cut into 3-4-mm pieces and mixed then transplanted subcutaneously within $30 \mathrm{~min}$ into three to six immunodeficient NSI mice. The tumor-implanted mice were observed daily for 90 days. Tumors were measured once a week by caliper to determine the subcutaneous growth rate. At a size of about $1 \mathrm{~cm}^{3}$, tumors were removed and passed on to other NSI mice. Tumors were passed on no more than 10 times.

\section{Statistical analyses}

Data were analyzed using GraphPad Prism 5 with the Student's $t$ test. $P$ values less than 0.05 were considered statistically significant. 


\section{Additional files}

Additional file 1: Figure S1. Establishment of K562-GFP and RMA-GFP cell line. A. Flow chart of establishing K562-GFP and RMA-GFP cells that that constitutively expressed green fluorescent protein (GFP). B. Representative fluorescence-activated cell sorting plots show K562-GFP and RMA-GFP cells before and after GFP+ enrichment.

Additional file 2: Figure S2. Experimental design for assessing the capabilities of leukemic (top) or solid (bottom) grafts in immunodeficient mice. Three groups of mice (five mice per group) were assayed; a high number $\left(1 \times 10^{6}, \mathrm{H}\right)$, medium number $\left(1 \times 10^{5}, \mathrm{M}\right)$, and low number $\left(1 \times 10^{4}, \mathrm{~L}\right)$ of grafts (K562-GFP, RMA-GFP, A549, and B16F10) were injected into NSI, IL2Rg-/-, NOD-scid, scid, Rag2-/-, nude, and WT mice.

Additional file 3: Table S1. The final TEl scores of NSI, NOD-scid, scid, nude, Rag2-/-, $/ L 2 R g-/-$, and WT mice measured by xenograft experiments.

Additional file 4: Table S2. The final TEI score of NSI, NOD-scid, IL2Rg-/-, Rag2-/-, scid, nude and WT mice measured by allograft experiments.

Additional file 5: Figure S3. Flow chart of the functional verification of NSI mice by establishing a BLT model. Sub-lethally irradiated NSI mice were transplanted with human fetal liver and thymus tissue from the same human donors, and engrafted with autologous CD34+ hematopoietic stem cells. BLT-NSI mice were tested with flow cytometry 12 weeks after engraftment. At 12 weeks, BLT-NSI mice were immunized with OVA twice and then the serum was analyzed for human $\operatorname{lgG}$.

Additional file 6: Figure S4. Tumors dissected from NSCLC PDX mice contained the bone marrow-derived cells of the hosts. Representative plots of FACS analysis show dissociated cells from the tumors contained both human cells $(\mathrm{HLA}+)$ and murine cells $(\mathrm{MHC}++)$ that were further subjected for analysis of murine Ly6g and CD11b expression.

Additional file 7: Figure S5. Generation and characterization of the lung cancer xenograft model using dissociated tumour cells in NSI mice. Primary tumors from NSCLC patients were digested and dissociated with trypsin and were subsequently injected into NSI mice. Representative hematoxylin and eosin-stained tissues of an adenocarcinoma (left) and corresponding early-generation xenografts (right); scale bar $=50 \mu \mathrm{m}$.

\section{Abbreviations}

TEl: Tumor engraftment index; WT: C57BL/6 wild type; Scid: Severe combined immunodeficiency; Rag2-/-: Recombination-activating 2 deficient; NOD-scid: NOD.Cg-Prkdc ${ }^{\text {scid. }}$; ll2Rg-/-: B6.129S4-IL2Rg-/-; NK: Natural killer;

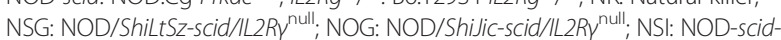
IL2Rg-/-; PBMCs: Peripheral blood mononuclear cells; HSCs: Hematopoietic stem cells; ZFN: Zinc-finger nuclease; TALEN: Transcription activator-like effector nuclease; CRISPR: Clustered regularly interspaced short palindromic repeats; Cas: CRISPR associated; BLT: Bone marrow/liver/thymus; B-ALL: B cell acute lymphoblastic leukemia; PDX: Patient-derived xenograft; WT: Wild type; BM: Bone marrow; SP: Spleen; PB: Peripheral blood; OVA: Ovalbumin; NSCLC: Non-small cell lung cancer.

\section{Competing interests}

The authors declare that they have no competing interests.

\section{Authors' contributions}

$\mathrm{PL}, \mathrm{DP}$, and $\mathrm{WY}$ conceived the study and designed the experiments. WY and $S L$ performed most of the transplantation experiments using cell lines. YX and WY performed the lung cancer PDX experiments. ZJ performed the B-ALL single-cell transplantation experiments. $Y L, G L, B X, H Y, L X$, and $Y L$ provided and prepared B-ALL samples. BJ, MZ, HY, ZL, and SC provided and prepared cord blood samples. ZH, JL, FF, and ZW provided and prepared lung cancer patient samples. DW, LZ, and PL contributed the discussion part of the manuscript. YY provided vital new reagents and revised the manuscript. WY, YX, PL, and DP discussed and wrote the manuscript. All authors read and approved the final manuscript.

\section{Acknowledgments}

This study was supported in part by the Strategic Priority Research Program of the Chinese Academy of Sciences (Grant No. XDA01020310), the National
Natural Science Foundation of China (Grant No. 81272329,81200255 to P. L., 81327801 to D. W.), National Basic Research Program of China (973 Program) (2013CB967100 to L. Z.), Science Fund for Distinguished Young Scholars of Guangdong Province, China (2014A030306028 to P. L.), and Research and Development Fund for Strategic Cooperation between Chinese Academy of Sciences and Guangdong Province (2013B091000010).

\section{Author details}

${ }^{1}$ Key Laboratory of Regenerative Biology, South China Institute for Stem Cell Biology and Regenerative Medicine, Guangzhou Institutes of Biomedicine and Health, Chinese Academy of Sciences, Guangzhou 510530, China. ${ }^{2}$ Guangdong Provincial Key Laboratory of Stem Cell and Regenerative Medicine, South China Institute for Stem Cell Biology and Regenerative Medicine, Guangzhou Institutes of Biomedicine and Health, Chinese Academy of Sciences, Guangzhou 510530, China. ${ }^{3}$ Department of General Surgery, The Second Hospital of Yulin, Yulin, Shaanxi Province 719000, China. ${ }^{4}$ Department of Obstetrics and Gynecology, Nanfang Hospital, Southern Medical University, Guangzhou 510515, China. ${ }^{5}$ Department of Hematology, Nanfang Hospital, Southern Medical University, Guangzhou 510515, China. ${ }^{6}$ Department of Thoracic Oncology, Sun Yat-Sen University Cancer Center, Guangzhou, China. ${ }^{7}$ State Key Laboratory of Oncology in South China, Collaborative Innovation Center of Cancer Medicine, Guangzhou, China. ${ }^{8}$ State Key Laboratory of Respiratory Disease, The First Affiliate Hospital of Guangzhou Medical University, Guangzhou, China. ${ }^{9}$ Department of Pathology, School of Basic Medical Sciences, Guangzhou Medical University, Guangzhou 510182, China. ${ }^{10}$ Department of Outpatient, The 91th Military Hospital, Jiaozuo 454003, China. ${ }^{11}$ Division of Reproductive Endocrinology, The 91th Military Hospital, Jiaozuo 454003, China. ${ }^{12}$ Division of General Pediatrics, The 91 th Military Hospital, Jiaozuo 454003, China. ${ }^{13}$ Institute of Hematology, Medical College, Jinan University, Guangzhou 510632, China. ${ }^{14}$ Key Laboratory for Regenerative Medicine of Ministry of Education, Jinan University, Guangzhou 510632, China. ${ }^{15}$ Wellcome Trust Sanger Institute, Hinxton, Cambridge CB10 1HH, England, UK. ${ }^{16}$ Drug Discovery Pipeline, Guangzhou Institutes of Biomedicine and Health, Chinese Academy of Sciences, Guangzhou 510530, China. ${ }^{17}$ Guangzhou Institutes of Biomedicine and Health, Chinese Academy of Sciences, 190 Kaiyuan Avenue, Science Park, Guangzhou, Guangdong 510530, China.

Received: 17 February 2015 Accepted: 13 May 2015

Published online: 29 May 2015

\section{References}

1. Ehrlich D, Wang B, Lu W, Dowling P, Yuan R. Intratumoral anti-HuD immunotoxin therapy for small cell lung cancer and neuroblastoma. J Hematol Oncol. 2014;7(1):91. doi:10.1186/s13045-014-0091-3.

2. Flanagan SP. 'Nude', a new hairless gene with pleiotropic effects in the mouse. Genet Res. 1966;8(3):295-309.

3. Bosma GC, Custer RP, Bosma MJ. A severe combined immunodeficiency mutation in the mouse. Nature. 1983;301(5900):527-30.

4. Shinkai Y, Rathbun G, Lam KP, Oltz EM, Stewart V, Mendelsohn M, et al. RAG-2-deficient mice lack mature lymphocytes owing to inability to initiate V(D)J rearrangement. Cell. 1992;68(5):855-67.

5. Shultz LD, Schweitzer PA, Christianson SW, Gott B, Schweitzer IB, Tennent B, et al. Multiple defects in innate and adaptive immunologic function in NOD/LtSz-scid mice. J Immunol. 1995;154(1):180-91.

6. Ito M, Hiramatsu H, Kobayashi K, Suzue K, Kawahata M, Hioki K, et al. NOD/SCID/gamma(c)(null) mouse: an excellent recipient mouse model for engraftment of human cells. Blood. 2002;100(9):3175-82. doi:10.1182/ blood-2001-12-0207.

7. Shultz LD, Lyons BL, Burzenski LM, Gott B, Chen X, Chaleff S, et al. Human lymphoid and myeloid cell development in NOD/LtSz-scid IL2R gamma null mice engrafted with mobilized human hemopoietic stem cells. J Immunol. 2005;174(10):6477-89.

8. Dunn GP, Bruce AT, Ikeda H, Old LJ, Schreiber RD. Cancer immunoediting: from immunosurveillance to tumor escape. Nat Immunol. 2002;3(11):991-8. doi:10.1038/ni1102-991.

9. Ji X, Zhang L, Peng J, Hou M. T cell immune abnormalities in immune thrombocytopenia. J Hematol Oncol. 2014;7(1):72. doi:10.1186/s13045-0140072-6.

10. Penn I. Tumors of the immunocompromised patient. Annu Rev Med 1988;39:63-73. doi:10.1146/annurev.med.39.1.63. 
11. Shankaran V, Ikeda H, Bruce AT, White JM, Swanson PE, Old LJ, et al. IFNgamma and lymphocytes prevent primary tumour development and shape tumour immunogenicity. Nature. 2001;410(6832):1107-11. doi:10.1038/35074122.

12. Kaplan DH, Shankaran V, Dighe AS, Stockert E, Aguet M, Old LJ, et al. Demonstration of an interferon gamma-dependent tumor surveillance system in immunocompetent mice. Proc Natl Acad Sci U S A. 1998:95(13):7556-61. doi:10.1073/pnas.95.13.7556.

13. Mali P, Yang L, Esvelt KM, Aach J, Guell M, DiCarlo JE, et al. RNA-guided human genome engineering via Cas9. Science. 2013;339(6121):823-6. doi:10.1126/science.1232033.

14. Urnov FD, Rebar EJ, Holmes MC, Zhang HS, Gregory PD. Genome editing with engineered zinc finger nucleases. Nat Rev Genet. 2010;11(9):636-46. doi:10.1038/nrg2842.

15. de Souza N. Improving gene-editing nucleases. Nat Methods. 2012;9(6):536. doi:10.1038/nmeth.2060.

16. Baker M. Gene-editing nucleases. Nat Methods. 2012;9(1):23-6.

17. Xiao Y, Wei X, Jiang Z, Wang X, Ye W, Liu X, et al. Loss of Angiopoietin-like 7 diminishes the regeneration capacity of hematopoietic stem and progenitor cells. J Hematol Oncol. 2015;8(1):7. doi:10.1186/s13045-014-0102-4.

18. Cong L, Ran FA, Cox D, Lin S, Barretto R, Habib N, et al. Multiplex genome engineering using CRISPR/Cas systems. Science. 2013;339(6121):819-23. doi:10.1126/science.1231143.

19. Fujita T, Fujii H. Efficient isolation of specific genomic regions and identification of associated proteins by engineered DNA-binding molecule-mediated chromatin immunoprecipitation (enChIP) using CRISPR. Biochem Biophys Res Commun. 2013;439(1):132-6. doi:10.1016/j.bbrc.2013.08.013.

20. Fujii W, Onuma A, Sugiura K, Naito K. Efficient generation of genome-modified mice via offset-nicking by CRISPR/Cas system. Biochem Biophys Res Commun. 2014;445(4):791-4. doi:10.1016/j.bbrc.2014.01.141.

21. Zhou J, Shen B, Zhang W, Wang J, Yang J, Chen L, et al. One-step generation of different immunodeficient mice with multiple gene modifications by CRISPR/Cas9 mediated genome engineering. Int J Biochem Cell Biol. 2014:46:49-55. doi:10.1016/j.biocel.2013.10.010.

22. Agliano A, Martin-Padura I, Mancuso P, Marighetti P, Rabascio C, Pruneri G, et al. Human acute leukemia cells injected in NOD/LtSz-scid/IL-2Rgamma null mice generate a faster and more efficient disease compared to other NOD/scid-related strains. Int J Cancer. 2008;123(9):2222-7. doi:10.1002/ ijc.23772.

23. Machida K, Suemizu H, Kawai K, Ishikawa T, Sawada R, Ohnishi Y, et al. Higher susceptibility of NOG mice to xenotransplanted tumors. J Toxicol Sci. 2009:34(1):123-7.

24. Cao X, Shores EW, Hu-Li J, Anver MR, Kelsall BL, Russell SM, et al. Defective lymphoid development in mice lacking expression of the common cytokine receptor gamma chain. Immunity. 1995;2(3):223-38.

25. Xiao $Y$, Jiang $Z$, Li $Y$, Ye $W$, Jia B, Zhang $M$, et al. ANGPTL7 regulates the expansion and repopulation of human hematopoietic stem and progenitor cells. Haematologica. 2015. doi: 10.3324/haematol.2014.118612.

26. Klein E, Ben-Bassat $H$, Neumann H, Ralph P, Zeuthen J, Polliack A, et al. Properties of the K562 cell line, derived from a patient with chronic myeloid leukemia. Int J Cancer. 1976;18(4):421-31.

27. Lindberg J, Martin-Fontecha A, Hoglund P. Natural killing of MHC class I(-) lymphoblasts by NK cells from long-term bone marrow culture requires effector cell expression of Ly49 receptors. Int Immunol. 1999;11(8):1239-46.

28. Giard DJ, Aaronson SA, Todaro GJ, Arnstein P, Kersey JH, Dosik H, et al. In vitro cultivation of human tumors: establishment of cell lines derived from a series of solid tumors. J Natl Cancer Inst. 1973;51(5):1417-23.

29. Gautam A, Waldrep JC, Densmore CL, Koshkina N, Melton S, Roberts L, et al. Growth inhibition of established B16-F10 lung metastases by sequential aerosol delivery of p53 gene and 9-nitrocamptothecin. Gene Ther. 2002;9(5):353-7. doi:10.1038/sj.gt.3301662.

30. Fichtner I, Rolff J, Soong R, Hoffmann J, Hammer S, Sommer A, et al. Establishment of patient-derived non-small cell lung cancer xenografts as models for the identification of predictive biomarkers. Clin Cancer Res. 2008;14(20):6456-68. doi:10.1158/1078-0432.Ccr-08-0138.

31. Merk J, Rolff J, Becker M, Leschber G, Fichtner I. Patient-derived xenografts of non-small-cell lung cancer: a pre-clinical model to evaluate adjuvant chemotherapy? Eur J Cardiothorac Surg. 2009;36(3):454-9. doi:10.1016/ j.ejcts.2009.03.054.

32. Ilie M, Nunes $M$, Blot L, Hofman V, Long-Mira E, Butori C, et al. Setting up a wide panel of patient-derived tumor xenografts of non-small cell lung cancer by improving the preanalytical steps. Cancer Med. 2014. doi:10.1002/cam4.357.

33. Kumar H, Kawai T, Akira S. Toll-like receptors and innate immunity. Biochem Biophys Res Commun. 2009;388(4):621-5. doi:10.1016/j.bbrc.2009.08.062.

34. Janeway Jr CA, Medzhitov R. Innate immune recognition. Annu Rev Immunol. 2002;20:197-216. doi:10.1146/annurev.immunol.20.083001.084359.

35. Workman P, Aboagye EO, Balkwill F, Balmain A, Bruder G, Chaplin DJ, et al. Guidelines for the welfare and use of animals in cancer research. $\mathrm{Br}$ J Cancer. 2010;102(11):1555-77. doi:10.1038/sj.bjc.6605642.

\section{Submit your next manuscript to BioMed Central and take full advantage of:}

- Convenient online submission

- Thorough peer review

- No space constraints or color figure charges

- Immediate publication on acceptance

- Inclusion in PubMed, CAS, Scopus and Google Scholar

- Research which is freely available for redistribution 